\title{
Effect of oral calcium loading on intact PTH and calcitriol in idiopathic renal calcium stone formers and healthy controls
}

\author{
B. Hess ${ }^{1}$, K. Lippuner ${ }^{1}$, R. Takkinen ${ }^{1}$, L. Villiger ${ }^{1}$, D. Ackermann ${ }^{2}$ and P. Jaeger ${ }^{1}$ \\ ${ }^{1}$ Policlinic of Medicine and ${ }^{2}$ Department of Urology, University of Berne, Switzerland
}

\begin{abstract}
The calciuric response after an oral calcium load ( $1000 \mathrm{mg}$ elemental calcium together with a standard breakfast) was studied in 13 healthy male controls and 21 recurrent idiopathic renal calcium stone formers, 12 with hypercalciuria $\left(\mathrm{U}_{\mathrm{Ca}} \times\right.$ $\mathrm{V}>7.50 \mathrm{mmol} / 24 \mathrm{~h}$ ) and nine with normocalciuria. In controls, serum $1,25(\mathrm{OH})_{2}$ vitamin D3 (calcitriol) remained unchanged $6 \mathrm{~h}$ after oral calcium load $(50.6 \pm 5.1$ versus $50.9 \pm 5.0 \mathrm{pg} / \mathrm{ml})$, whereas it tended to increase in hypercalciuric (from $53.6 \pm 3.2$ to $60.6 \pm 5.4 \mathrm{pg} / \mathrm{ml}, P=0.182$ ) and fell in normocalciuric stone formers (from $45.9 \pm 2.6$ to $38.1 \pm 3.3 \mathrm{pg} / \mathrm{ml}$, $P=0.011)$. The total amount of urinary calcium excreted after OCL was $2.50 \pm 0.20 \mathrm{mmol}$ in controls, $2.27 \pm 0.27 \mathrm{mmol}$ in normocalciuric and $3.62 \pm$ $0.32 \mathrm{mmol}$ in hypercalciuric stone formers $(P=0.005$ versus controls and normocalciuric stone formers respectively); it positively correlated with serum calcitriol $6 \mathrm{~h}$ after calcium load $(r=0.392, P=0.024)$. Maximum increase in urinary calcium excretion rate, $\Delta \mathrm{Ca}-\mathrm{E}_{\max }$, was inversely related to intact $\mathrm{PTH}$ levels in the first $4 \mathrm{~h}$ after calcium load, i.e. more pronounced PTH suppression predicted a steeper increase in urinary calcium excretion rate. Twenty-four-hour urine calcium excretion rate was inversely related to the ratio of $\Delta$ calcitriol/ $\triangle \mathrm{PTH}_{\max }$ after calcium load $(r=-0.653, P=$ $0.0001)$, indicating that an abnormally up-regulated synthesis of calcitriol and consecutive relative PTH suppression induce hypercalciuria. Finally, late absorption of calcium as suggested by maximum urinary calcium excretion beyond $4 \mathrm{~h}$ after oral calcium load was as rare in hypercalciuric stone formers (2 of 12) as in controls ( 1 of 13) and did not occur in normocalciuric stone formers.
\end{abstract}

Key words: calcitriol; calcium nephrolithiasis; hypercalciuria; oral calcium load; PTH

\section{Introduction}

Idiopathic hypercalciuria can be found in about $50 \%$ of patients with calcium nephrolithiasis and $5 \%$ of

Correspondence and offprint requests to: $\mathrm{B}$. Hess MD, Policlinic of Medicine, University Hospital, $\mathrm{CH}-3010$ Berne, Switzerland. normal people [1,2]. A number of studies performed in the past (reviewed in [3]) provided evidence for elevated serum levels of $1,25(\mathrm{OH})_{2}$ vitamin D3 (calcitriol) as the primary event for idiopathic hypercalciuria. At least two mechanisms have been invoked to account for this finding: an inherited abnormality of the proximal tubular cell leading to up-regulation of calcitriol synthesis in hypercalciuric calcium stone formers (HCSF) (reviewed in [3]), or an increased monocytic production of interleukin 1 leading to a prostaglandin-mediated rise in calcitriol synthesis [4].

Increased calcitriol levels appear to predispose to hypercalciuria by raising intestinal calcium absorption. Indeed, the rise in urinary calcium excretion within $4 \mathrm{~h}$ after an oral calcium load (OCL) directly correlated with increased calcitriol levels in HCSF, when studied after 10 days on a low-calcium diet [5], and the calciuric response after OCL was also correlated with isotopic fractional intestinal absorption of calcium $[6,7]$.

Hypercalciuria raises urinary supersaturation, which is a prerequisite for calcium stone formation in the urinary tract $[8,9]$. Commonly, however, supersaturation is intermittent throughout a 24 -h period [9]; thus normal 24 -h excretion rates may not reflect periods of intermittent urinary supersaturation, and the classically used 4-h post-calcium-load excretory rates may be too short for that purpose.

The present 6-h calcium load study has been designed (1) to assess calcium metabolism for $6 \mathrm{~h}$ after OCL in HCSF, normocalciuric calcium stone formers (NCSF) and controls (C) while on free-choice diet; and (2) to test the hypothesis of occurrence of delayed intermittent hypercalciuria after OCL (late absorbers).

\section{Subjects and methods}

Among the patients seen for metabolic work-up at our renal stone clinic, we selected 21 male recurrent calcium stone formers (RCSF) meeting the following criteria: (1) passage of at least two calcium-containing stones, defined either by stone analysis (X-ray diffraction or infrared spectroscopy) or disappearance of opaque material on conventional radiographs and excretory urograms; (2) true idiopathic calcium 
stone disease, i.e. exclusion according to the previously published protocol [10] of established causes of calcium stone formation such as primary hyperparathyroidism, medullary sponge kidney, overt distal renal tubular acidosis, sarcoidosis, excessive vitamin D intake, hypercalciuria due to hypercalcaemia (malignancy or immobilisation), and primary or enteric hyperoxaluria; (3) plasma creatinine concentration $<115 \mu \mathrm{mol} / 1$ ); and (4) absence of urinary tract infection, any renal disease other than nephrolithiasis, or bone disease.

All RCSF underwent our standard protocol for metabolic evaluation not prior to 2 months after urological intervention and while adhering to their individual free-choice diet, as previously described [10]. Metabolic work-up consisted of sampling fasting venous blood and $2-\mathrm{h}$ urine after $12 \mathrm{~h}$ without eating and $8 \mathrm{~h}$ without drinking (only tap water allowed after last meal). Every patient collected two 24-h urines. RCSF were interviewed by their physicians for dietary habits only once both collections had been completed. This is to avoid influencing dietary habits before urine collections have been completed. An estimate of daily calcium intake from dairy products was obtained using a questionnaire based on dairy products regularly consumed in Switzerland and a table of their calcium content [11].

All RCSF were kept on free-choice diet and underwent the oral calcium loading study (OCL), as did 13 healthy male volunteers without any evidence of kidney or bone disease (C); additionally, nine of $13 \mathrm{C}$ collected one 24-h urine while adhering to their free-choice diet. Informed consent was obtained from every participant before OCL. On the evening prior to the study, subjects were not allowed to eat later than at 7.00 p.m. Until midnight, they drank 0.51 of tap water. On the morning of the study day, subjects voided the bladder at 6.00 a.m. and remained fasting. After arriving at the Clinical Investigation Unit of the Policlinic of Medicine at 8.00 a.m., an indwelling catheter was placed in an antecubital vein, from where fasting blood was drawn, and 2-h fasting urine was collected. Thereafter, subjects received a standard breakfast ( $130 \mathrm{~g}$ dark bread, $40 \mathrm{~g}$ butter, $50 \mathrm{~g}$ jam) together with $1000 \mathrm{mg}$ elemental calcium as calcium-gluconolactate/calcium carbonate (Calcium-Sandoz ff, Sandoz Pharmaceutical Company, Basle, Switzerland), given as an effervescent solution in 0.51 of distilled water. Fifteen and $30 \mathrm{~min}$ after breakfast had been ingested, blood was drawn for measurements of ionized calcium and intact PTH. Thereafter, blood and urine samples were collected hourly during $6 \mathrm{~h}$. Subjects remained recumbent except for voiding the bladder every hour. They received 0.21 of distilled water hourly throughout the study.

Plasma concentrations of creatinine, urea, total calcium, phosphate, magnesium, sodium, potassium, chloride, uric acid, albumin, and total protein were measured by autoanalyser techniques. In whole blood, ionized calcium was measured by an ion-selective electrode (Ciba-Corning Diagnostics Corp., Medfield, MA, USA), and venous blood gas analysis was performed by a Ciba-Corning 278 blood gas system (Ciba-Corning Diagnostics) immediately after sampling without compression. Intact PTH (normal values $10-65 \mathrm{pg} / \mathrm{ml}$ ) was measured in serum using an immunoradiometric assay kit (Nichols Institute, San Juan Capistrano, CA, USA). Serum 25(OH) vitamin D3 (25(OH)D3) and serum 1,25 $(\mathrm{OH})_{2}$ vitamin D3 (Calcitriol) were also measured by immunoradiometric assays (Nichols Institute). Normal values, obtained from 60 healthy volunteers ( 30 males, 30 females) in the area of Berne, were $6-40 \mathrm{ng} / \mathrm{ml}$ for $25(\mathrm{OH}) \mathrm{D} 3$ and $25-79 \mathrm{pg} / \mathrm{ml}$ for calcitriol respectively.

Twenty-four hour as well as 2-h fasting urine samples were analysed for calcium, phosphate, magnesium, sodium, potas- sium, chloride, uric acid, urea and creatinine by autoanalyser techniques. Oxalate was measured after enzymatic oxidation by oxalate oxidase [12], citrate using the citrate lyase method [13], and sulphate by an HPLC system [14], as previously described [10].

Urine $\mathrm{pH}$ was measured immediately after voiding using a Metrohm 654 pH-Meter (Metrohm, Herisau, Switzerland) Hydroxyproline (OHP) was measured using a kit (Hypronosticon ${ }^{\circledR}$, Organon Teknika, Boxtel, The Netherlands) where OHP is coloured by Ehrlich's reagent and quantified photometrically after binding to an acid cation exchange resin, hydrolysis for $16 \mathrm{~h}$ and oxidation.

In 2-h fasting urines as well as in hourly urines after calcium loading, urinary calcium output (mmol/period) was calculated as $\left[\mathrm{U}_{\mathrm{Ca}}\right] \times$ volume, and excretions of calcium as well as OHP were expressed as $\mathrm{Ca}-\mathrm{E}\left(=\mathrm{U}_{\mathrm{Ca}} / \mathrm{U}_{\mathrm{Crea}} \times\right.$ $\left.\mathrm{P}_{\text {Crea }}, \mathrm{mmol} / \mathrm{l} \mathrm{GF}\right)$ and OHP-E $\left(=\mathrm{U}_{\mathrm{OHP}} / \mathrm{U}_{\mathrm{Crea}} \times \mathrm{P}_{\text {Crea }}\right.$, $\mu \mathrm{mol} / \mathrm{l} \mathrm{GF}$ ) respectively. Based on measurements in fasting blood and 2-h fasting urine samples, renal phosphate threshold (TmP/GFR) was derived from the nomogram of Walton and Bijvoet [15].

Twenty-four hour urines were collected in 3-litre plastic bottles containing $10 \mathrm{~g}$ of boric acid as a preservative agent [10]. All individual 24-h urine values of RCSF are presented as the mean of two urine collections. According to the 24-h urinary excretion rate of calcium $\left(\mathrm{U}_{\mathrm{Ca}} \times \mathrm{V}\right), \mathrm{RCSF}$ were divided into hypercalciurics (HCSF) and normocalciurics (NCSF); hypercalciuria was arbitrarily defined as $U_{\mathrm{Ca}} \times \mathrm{V}>7.50 \mathrm{mmol} / 24$, as originally described by Hodgkinson and Pyrah [16].

All values are presented as means $\pm S E$. Non-parametric Mann-Whitney U test for comparisons between single groups and ANOVA for repeated measurements for inter-group comparisons as well as simple regression analysis for correlation studies were used.

\section{Results}

Table 1 summarizes the basal characteristics of all study participants; among the $21 \mathrm{RCSF}, 12$ were $\mathrm{HCSF}$, and nine were NCSF. There was no significant difference in calcium intake from dairy products between HCSF and NCSF. Compared with both $\mathrm{HCSF}$ and $\mathrm{C}$, plasma creatinine concentration was elevated in NCSF; however, it remained within the normal range. For similar levels of ionized calcium

Table 1. Basic characteristics of 34 subjects (C, HCSF and NCSF) before OCL.

\begin{tabular}{llcl}
\hline & C (13) & NCSF (9) & HCSF (12) \\
\hline Age (years) & $41.9 \pm 2.7$ & $44.9 \pm 2.3$ & $39.3 \pm 2.2$ \\
$\mathrm{Ca}$ intake (dairy & n.d. & $18.2 \pm 1.6$ & $13.7 \pm 5.0$ \\
$\quad$ prod., mmol/d) & & & \\
$\mathrm{P}_{\mathrm{Crea}}(\mu \mathrm{mol} / \mathrm{l})$ & $92.9 \pm 3.1$ & $104.6 \pm 2.9 \dagger$ & $87.1 \pm 3.1^{*}$ \\
$\mathrm{Ca}^{2+}(\mathrm{mmol} / \mathrm{l})$ & $1.28 \pm 0.01$ & $1.27 \pm 0.03$ & $1.27 \pm 0.01$ \\
$\mathrm{P}_{\mathrm{Ph}}(\mathrm{mmol} / \mathrm{l})$ & $0.96 \pm 0.04$ & $0.81 \pm 0.07$ & $0.86 \pm 0.05$ \\
Intact-PTH $(\mathrm{pg} / \mathrm{ml})$ & $25.7 \pm 2.1$ & $24.8 \pm 2.6$ & $23.1 \pm 2.6$ \\
$25-\mathrm{OH}-\mathrm{D} 3(\mathrm{ng} / \mathrm{ml})$ & $21.2 \pm 1.5$ & $25.7 \pm 1.8$ & $22.6 \pm 2.0$ \\
$\mathrm{Calcitriol}(\mathrm{pg} / \mathrm{ml})$ & $50.6 \pm 5.1$ & $42.3 \pm 3.1$ & $56.3 \pm 4.0+$ \\
\hline
\end{tabular}

Values are means $\pm \mathrm{SEM} . \dagger P=0.039$ versus $\mathrm{C} ;{ }^{*} P=0.005$ versus C. 
plasma phosphate, intact PTH and 25(OH)-vitamin D3 between the three groups, serum calcitriol was higher in HCSF than in NCSF.

Table 2 depicts the results of various measurements in 2-h fasting urines. Compared with $\mathrm{C}$, NCSF had lower TmP/GFR values, whereas $\mathrm{HCSF}$ had high fasting urinary excretion of calcium. Fasting OHP-E as well as urinary oxalate/creatinine and sodium/creatinine concentration ratios were not different between the three groups. Fasting Ca-E $(r=0.460, P=0.006)$ as well as fasting urinary $\mathrm{Ca} / \mathrm{Crea}(r=0.393, P=0.021)$ were positively correlated with fasting urinary $\mathrm{Na} / \mathrm{Crea}$. Fasting urinary $\mathrm{Ca} / \mathrm{Crea}$ also correlated with 24-h urine $\mathrm{Ca} / \mathrm{Crea}(r=0.538, P=0.002)$. Moreover, the total amount of calcium excreted in 2-h fasting urines $(\mathrm{mmol} / 2 \mathrm{~h})$ positively correlated with baseline calcitriol levels in RCSF $(r=0.508, P=0.022)$.

Twenty-four-hour urine data are summarized in Table 3. Urine volume $(P<0.05)$ as well as 24 -h urinary excretion rates of calcium $(P<0.001)$ and of phosphate $(P<0.025)$ were higher in HCSF than in $\mathrm{C}$; the latter parameter was also higher than in NCSF $(P<0.05)$. When the $P / C r e a$ ratio $(\mathrm{mmol} / \mathrm{mmol})$ was calculated, no significant differences remained, either between

Table 2. Fasting urine measurements in 34 subjects (C, HCSF and NCSF) before OCL

\begin{tabular}{llll}
\hline & $\mathrm{C}(13)$ & NCSF (9) & HCSF (12) \\
\hline $\begin{array}{ccc}\text { Fasting U } \\
\text { TmP/GFR } \\
(\mathrm{mmol} / 1 \mathrm{GF})\end{array}$ & $\begin{array}{l}6.05 \pm 0.25 \\
\text { Fasting Ca-E } \\
\quad(\mu \mathrm{mol} / \mathrm{l} \mathrm{GF})\end{array}$ & $0.023 \pm 0.057 \pm 0.15$ & $6.03 \pm 0.26$ \\
$\begin{array}{c}\text { Fasting OHP-E } \\
(\mu \mathrm{mol} / \mathrm{l} \mathrm{GF})\end{array}$ & $1.25 \pm 0.16$ & $0.73 \pm 0.04^{*}$ & $0.87 \pm 0.05$ \\
$\begin{array}{c}\text { Fasting Ox/Crea } \\
(\mu \mathrm{mol} / \mathrm{mmol})\end{array}$ & $15.5 \pm 3.3$ & $18.7 \pm 4.3$ & $22.1 \pm 5.3$ \\
$\begin{array}{c}\text { Fasting Na/Crea } \\
(\mathrm{mmol} / \mathrm{mmol})\end{array}$ & $8.86 \pm 0.91$ & $9.42 \pm 2.38$ & $9.91 \pm 1.33$ \\
\hline
\end{tabular}

Values are means $\pm \mathrm{SEM} . \dagger P=0.039$ versus $\mathrm{C} ;{ }^{*} P=0.005$ versus C.

Table 3. Twenty-four-hour urine measurements in $\mathrm{C}$ (available in nine subjects), HCSF $(n=12)$ and $\operatorname{NCSF}(n=9)$

\begin{tabular}{lccc}
\hline & $\mathrm{C}$ & $\mathrm{NCSF}$ & $\mathrm{HCSF}$ \\
\hline & $1318 \pm 202$ & $1995 \pm 229$ & $2033 \pm 229^{\circ}$ \\
Volume (ml/day) & $4.8 \pm 0.6$ & $5.2 \pm 0.4$ & $10.2 \pm 0.7^{* *}$ \\
$\mathrm{U}_{\mathrm{Ca}} \times \mathrm{V}$ & $28.9 \pm 1.7$ & $29.2 \pm 2.2$ & $35.3 \pm 1.5 \dagger^{*}$ \\
$\mathrm{U}_{\mathrm{P}} \times \mathrm{V}$ & $399 \pm 39$ & $437 \pm 26$ & $400 \pm 25$ \\
$\mathrm{U}_{\mathrm{Urea}} \times \mathrm{V}$ & $21.4 \pm 1.1$ & $20.7 \pm 1.3$ & $21.3 \pm 1.3$ \\
$\mathrm{U}_{\mathrm{Sulf}} \times \mathrm{V}$ & $3.2 \pm 0.3$ & $4.1 \pm 0.3$ & $3.5 \pm 0.25$ \\
$\mathrm{U}_{\mathrm{UA}} \times \mathrm{V}$ & $13.5 \pm 0.9$ & $15.4 \pm 0.8$ & $16.4 \pm 0.8$ \\
$\mathrm{U}_{\mathrm{Crea}} \times \mathrm{V}$ & $274 \pm 59$ & $339 \pm 39$ & $354 \pm 54$ \\
$\mathrm{U}_{\mathrm{Ox}} \times \mathrm{V}(\mu \mathrm{mol} / \mathrm{day})$ & $193 \pm 31$ & $224 \pm 21$ & $213 \pm 27$ \\
$\mathrm{U}_{\mathrm{Na}} \times \mathrm{V}$ & $4.2 \pm 0.5$ & $4.0 \pm 0.5$ & $4.9 \pm 0.5$ \\
$\mathrm{U}_{\mathrm{Mg}} \times \mathrm{V}$ & $3.3 \pm 0.5$ & $2.6 \pm 0.2$ & $3.2 \pm 0.3$ \\
$\mathrm{U}_{\mathrm{Cit}} \times \mathrm{V}$ & & & \\
\hline
\end{tabular}

All values are in mmol/day (means $\pm \mathrm{SEM}$ ) except where otherwise indicated. ${ }^{\circ} P<0.05$ versus $C ;+P<0.025$ versus $C ;{ }^{*} P<0.05$ versus NCSF; ${ }^{* *} P<0.001$ versus NCSF and versus $C$
$\operatorname{HCSF}(2.18 \pm 0.11)$ and $C(2.18 \pm 0.13)$ or between HCSF and NCSF $(1.89 \pm 0.10, P=0.118) . \mathrm{U}_{\mathrm{Ca}} \times \mathrm{V}$ positively correlated with $\mathrm{U}_{\mathrm{Na}} \times \mathrm{V}(r=0.389, P=$ $0.034)$. Whereas urinary creatinine excretion rates were not different between subgroups, $\mathrm{C}_{\text {crea }}$ amounted to $115.1 \pm 5.2 \mathrm{ml} / \mathrm{min} / 1.73 \mathrm{~m}^{2}$ in HCSF, compared with $94.8 \pm 4.1 \mathrm{ml} / \mathrm{min} / 1.73 \mathrm{~m}^{2}$ in NCSF $(P=0.004)$.

After OCL, whole blood ionized calcium was at no time significantly different between subgroups. Figure 1 represents the OCL-induced deviations from baseline for mean $\mathrm{Ca}^{2+}$ and intact PTH concentrations in the three subgroups. The increase in $\mathrm{Ca}^{2+}$ occurred first in HCSF, followed by NCSF, and started only after $30 \mathrm{~min}$ in $\mathrm{C}$ (Figure 1, upper panel). The difference between $\mathrm{Ca}^{2+}$ at $1 / 2 \mathrm{~h}$ and at time $0, \Delta \mathrm{Ca}^{2+}{ }_{1 / 2-0}$, was higher in $\mathrm{HCSF}$ than in $\mathrm{C}(0.030 \pm 0.011$ versus $0.001 \pm 0.010 \mathrm{mmol} / \mathrm{l}, P=0.046)$, whereas the value in NCSF $(0.017 \pm 0.018 \mathrm{mmol} / 1)$ was different neither from HCSF nor from $\mathrm{C}$. When considering deviations of $\mathrm{Ca}^{2+}$ concentrations with time during the whole $360 \mathrm{~min}$ after OCL (areas under the curves), values were $11.5 \pm 3.4 \mathrm{mmol} / \mathrm{l} \times \min$ in $\mathrm{C}, 13.6 \pm 6.7 \mathrm{mmol} /$ $1 \times \min$ in NCSF, and $13.8 \pm 3.9 \mathrm{mmol} / 1 \times$ min in HCSF (NS for all comparisons). During the first $60 \mathrm{~min}$ after OCL, however, areas under the curves were $0.49 \pm 0.26 \mathrm{mmol} / 1 \times \mathrm{min}$ in C, $0.74 \pm 0.45 \mathrm{mmol} /$ $1 \times \mathrm{min}$ in $\mathrm{NCSF} \quad(P=0.664$ versus $\mathrm{C})$, and $1.81 \pm 0.55 \mathrm{mmol} / 1 \times \mathrm{min}$ in $\mathrm{HCSF}(P=0.054$ versus NCSF and $P=0.041$ versus $C$ ).
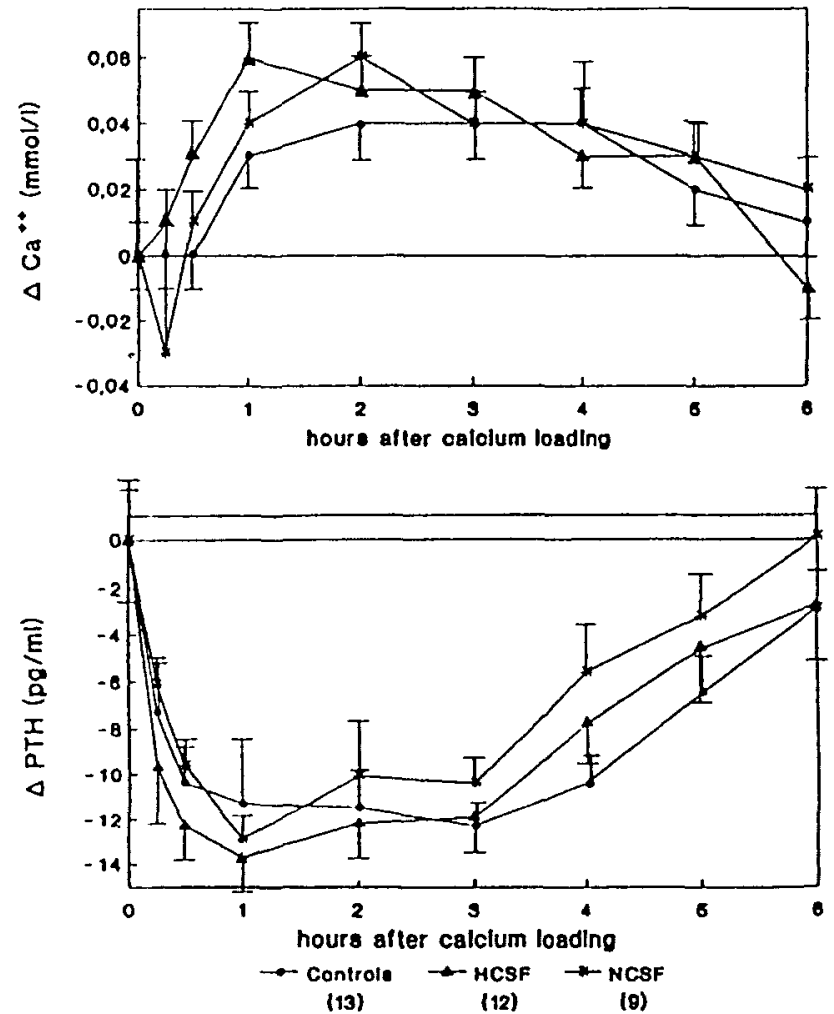

Fig. 1. Mean deviations from baseline values of $\mathrm{Ca}^{2+}$ (upper panel) and intact PTH (lower panel) after oral calcium load ( $1 \mathrm{~g}$ ) in controls (stars). NCSF (circles), and HCSF (triangles). Values are means $\pm S E M$. 
When using ANOVA for repeated measurements, intergroup differences in serum intact PTH after OCL were not significant. At 15 and $30 \mathrm{~min}$ after OCL, however, intact PTH was lower in HCSF $(13.4 \pm 2.4$ and $10.8 \pm 1.6 \mathrm{pg} / \mathrm{ml}$ respectively) than in NCSF $(18.7 \pm 1.2$ and $15.2 \pm 1.4 \mathrm{pg} / \mathrm{ml}$ respectively, $P<0.05$ for both comparisons, Mann-Whitney $U$ test). The total deviation of intact PTH from baseline over $360 \mathrm{~min}$ (Figure 1, lower panel) was not different between the three groups; areas under the curves amounted to $-3377.9 \pm 329.5 \mathrm{pg} / \mathrm{ml} \times \min$ in $C$, $-3291.9 \pm 557.3 \mathrm{pg} / \mathrm{ml} \times \mathrm{min}$ in HCSF, and $-2636.7 \pm 673.6 \mathrm{pg} / \mathrm{ml} \times \mathrm{min}$ in NCSF (NS for all comparisons).

Serum calcitriol concentrations $6 \mathrm{~h}$ after OCL were unchanged in $\mathrm{C}(50.6 \pm 5.1 \mathrm{pg} / \mathrm{ml}$ before versus $50.9 \pm 5.0 \mathrm{pg} / \mathrm{ml}$ after OCL), tended to increase in $\mathrm{HCSF}(53.6 \pm 3.2 \mathrm{pg} / \mathrm{ml}$ before and $60.6 \pm 5.4 \mathrm{pg} / \mathrm{ml}$ after OCL, $P=0.182$ ) and fell in NCSF $(45.9 \pm 2.6 \mathrm{pg} / \mathrm{ml}$ before and $38.1 \pm 3.3 \mathrm{pg} / \mathrm{ml}$ after OCL, $P=0.011$ ). Thus after OCL, serum calcitriol concentration in NCSF was lower than in C $(P=$ $0.049)$ and in HCSF $(P=0.007)$. Deviations in serum calcitriol concentrations from baseline values at $6 \mathrm{~h}$ after OCL ( $\Delta$ calcitriol) were $0.3 \pm 2.9 \mathrm{pg} / \mathrm{ml}$ in $C$, $-4.2 \pm 0.9 \mathrm{pg} / \mathrm{ml}$ in NCSF, and $4.3 \pm 3.5 \mathrm{pg} / \mathrm{ml}$ in HCSF $(P=0.028$ versus NCSF). As depicted in Figure 2, there was an inverse correlation between the ratio $\Delta$ calcitriol/maximum change in PTH $(\Delta$ calcitriol $\left./ \Delta \mathrm{PTH}_{\max }\right)$ and $\mathrm{U}_{\mathrm{Ca}} \times \mathrm{V} \quad(r=-0.653, \quad P=$ 0.0001 ), i.e. those subjects in whom the increase in calcitriol following OCL was steepest in the presence of a marked fall in PTH were most hypercalciuric.

As demonstrated in Figure 3, hourly urinary calcium excretion in the first $5 \mathrm{~h}$ after OCL was higher in HCSF than in NCSF and in C $(P<0.05$ for all comparisons, ANOVA for repeated measurements); in

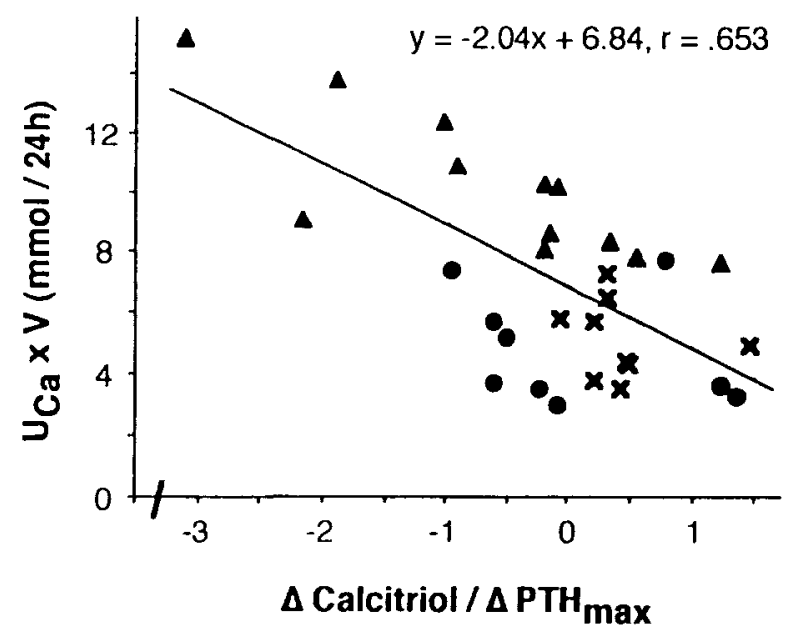

Fig. 2. Negative linear correlation $(r=-0.653, P=0.0001)$ between $\mathrm{U}_{\mathrm{Ca}} \times \mathrm{V}$ ( $y$ axis) and $\Delta$ calcitriol/ $\Delta \mathrm{PTH} \mathrm{H}_{\max }$ ratio ( $x$ axis). $\Delta$ calcitriol $=$ change in calcitriol concentrations between before and after OCL; $\Delta \mathrm{PTH}_{\max }=$ maximum decrease in PTH concentrations following OCL. Circles, $C$ ( 4 missing values, since subjects did not collect 24-hour urines); crosses, NCSF; triangles, HCSF.

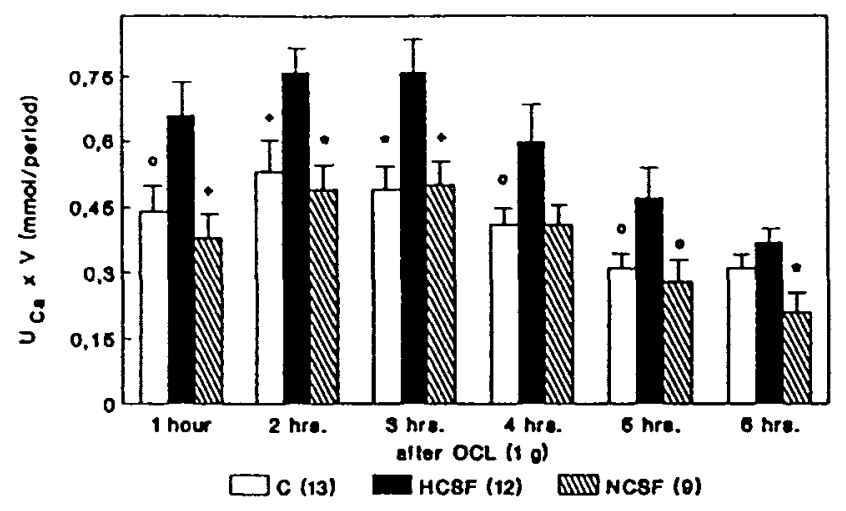

Fig. 3. Hourly urinary calcrum output (mmol/period) after oral calcium load $(1 \mathrm{~g})$ in controls, HCSF and NCSF. Values are means \pm SEM. ${ }^{\circ} P<0.05 ; \dagger P 0.025 ;{ }^{*} P<0.005$ versus HCSF.

the 6th hour after OCL, the difference remained significant only for HCSF versus NCSF $(P=0.012)$, but not for HCSF versus $C$. The total urinary calcium output after OCL amounted to $3.62 \pm 0.32 \mathrm{mmol}$ in HCSF, compared with $2.50 \pm 0.20 \mathrm{mmol}$ in $\mathrm{C}$ and $2.27 \pm 0.27 \mathrm{mmol}$ in NCSF $(P=0.005$ versus $C$ and NCSF respectively). It correlated positively with serum calcitriol levels $6 \mathrm{~h}$ after OCL $(r=0.392, P=0.024)$, but not with those before OCL $(r=0.309, P=0.081)$ nor with $\Delta$ calcitriol $(r=0.223, P=0.212)$.

Throughout the 6-h period after OCL, Ca-E differed among the three groups $(P=0.004$, ANOVA for repeated measurements), i.e. HCSF excreted more calcium than NCSF and C. However, the maximum increase in Ca-E from baseline, $\Delta \mathrm{Ca}-\mathrm{E}_{\max }$, was similar in all three groups, i.e. $0.057 \pm 0.005 \mu \mathrm{mol} / 1$ GF in $\mathrm{C}, \quad 0.052 \pm 0.008 \mu \mathrm{mol} / \mathrm{l}$ GF in NCSF, and $0.071 \pm 0.010 \mu \mathrm{mol} / 1 \mathrm{GF}$ in HCSF (NS for all comparisons). Furthermore Ca- $\mathrm{E}_{\max }$ tended to be inversely related to baseline values of intact PTH $(r=-0.336$, $P=0.052$ ), and the increase in Ca-E during the first hour after OCL also was inversely related to baseline intact PTH levels $(r=-0.348, P=0.044)$, i.e. subjects with lower PTH levels at baseline had steeper increases in Ca-E. Table 4 depicts that $\Delta \mathrm{Ca}-\mathrm{E}_{\max }$ inversely correlated with intact PTH values during the first $4 \mathrm{~h}$ after OCL.

Maximum hourly calcium excretion occurred during the 2nd hour after OCL in six C; in two of the $13 \mathrm{C}$,

Table 4. Inverse linear correlations between $\triangle \mathrm{Ca}-\mathrm{E}_{\max }$ and intact PTH levels after oral calcium loading (OCL)

\begin{tabular}{|c|c|c|c|}
\hline$y$ axis & $x$ axis & $r$ value & $P$ value \\
\hline$\triangle \mathrm{Ca}-\mathrm{E}_{\max }$ & $\begin{array}{l}\text { PTH }_{1 / 4 h} \\
\text { PTH }_{1 / 2 h} \\
\text { PTH }_{1 h} \\
\text { PTH }_{2 h} \\
\text { PTH }_{3 h} \\
\text { PTH }_{4 h} \\
\text { PTH }_{5 h} \\
\text { PTH }_{6 h}\end{array}$ & $\begin{array}{l}-0.412 \\
-0.419 \\
-0.360 \\
-0.440 \\
-0.384 \\
-0.388 \\
-0.164 \\
-0.307\end{array}$ & $\begin{array}{l}0.019 \\
0.014 \\
0.040 \\
0.009 \\
0.025 \\
0.024 \\
0.353 \\
0.078\end{array}$ \\
\hline
\end{tabular}

Subscripts denote time after OCL. 
however, maximum calcium excretion occurred later than $4 \mathrm{~h}$ after $\mathrm{OCL}$, i.e. during the 5th hour. Delayed increases in urinary calcium excretion could not be observed among the nine NCSF, of whom four had their highest urinary calcium output during the 2nd and three during the 3rd hour after OCL. Among the $12 \mathrm{HCSF}$, three had maximum calciuria already in the 1st hour after OCL, two in the 2nd, four in the 3rd, and two in the 4th hour; thus, late hypercalciuria occurred in only one of the $12 \mathrm{HCSF}$.

\section{Discussion}

The present study illustrates the fact that the magnitude of calciuric response after OCL is related to the degree of early parathyroid suppression and to post-load calcitriol levels, when subjects are studied under freechoice diet conditions.

Although OCL has originally been applied to distinguish between 'absorptive' and 'renal' types of idiopathic hypercalciuria [17], Coe et al. [18] convincingly demonstrated that these two patterns are not distinct entities, but rather two extremes of a continuous spectrum. Therefore, we did not attempt to separate 'absorptive' from 'renal' hypercalciurics based on fasting and post-load calciuria in this study, inasmuch as available data (reviewed in [1] and [3]) clearly suggest that the syndrome of idiopathic hypercalciuria always includes features of both intestinal hyperabsorption and reduced tubular reabsorption of calcium.

When comparing patterns of post-load blood calcium concentrations among subgroups (Figure 1), it is apparent that mean levels of blood ionized calcium first rise in HCSF, then in NCSF, and ultimately (after $30 \mathrm{~min}$ ) in C. In addition, calculations of areas under the curve demonstrate that the cumulative deviation of blood $\mathrm{Ca}^{2+}$ from baseline is greatest in HCSF only during the first hour, but not when considering the whole 6-h period after OCL that we studied. This earlier increment in blood calcium in HCSF is matched by lower PTH levels in these patients 15 and $30 \mathrm{~min}$ after the calcium load. The fact that PTH secretion is more suppressed in HCSF than in NCSF is in keeping with our recent finding of relative hypoparathyroidism in HCSF, compared with NCSF [10]. Parenthetically, our study also emphasizes the fact that the availability of the intact PTH assay has turned OCL into a suppression test of parathyroid secretion, what in the past had only indirectly been so by the mean of cyclic AMP measurements.

It is noteworthy that basal serum calcitriol levels were not predictive of the calciuric response after OCL in our subjects on free-choice diet. This is at variance with the findings obtained by Broadus et al. [5] who demonstrated a positive correlation between post-load calcium excretion and calcitriol levels when pooling data from NCSF and RCSF with absorptive hypercalciuria. Their specifically selected subjects, however, were studied after at least 10 days on a calciumrestricted diet $(400 \mathrm{mg}$ daily). Therefore calcitriol production had been stimulated by this manoeuvre, and actually calcitriol levels clearly exceeded the upper normal range in 40 of their $50 \mathrm{HCSF}$ and were highnormal in the other ones [5].

On the contrary, in the present study we deliberately evaluated RCSF under conditions of stone formation, i.e. while adhering to their free-choice diet. Therefore none of our HCSF exhibits serum calcitriol values above the upper limit of normal range (i.e. above $79 \mathrm{pg} / \mathrm{ml}$ ). Nevertheless, we confirm that calcitriol levels are elevated in HCSF, when compared with NCSF, which is consistent with data previously obtained in many investigations (reviewed in [3]). In addition we demonstrate that the calciuric response after OCL inversely relates to serum PTH concentrations, i.e. subjects with relative down-regulation of PTH secretion excrete more calcium after OCL. Together with the early increase in blood calcium that we observe in HCSF after OCL, this finding is compatible with an imbalance between calcitriol production and PTH secretion, leading to the following sequence of events: chronic up-regulation of calcitriol production raises active intestinal calcium absorption which is particularly marked in the duodenum [19]. The amount of calcium being absorbed early in the duodenum will be higher in subjects with elevated calcitriol levels, which may explain the earlier increase in blood calcium in HCSF; this in turn will lead to more pronounced PTH suppression which increases urinary calcium excretion.

In addition our study suggests a disordered control of calcitriol synthesis in at least some HCSF [20,21], compared to NCSF: despite an increase in blood ionized calcium and a decrease in intact PTH concentrations, both changes which certainly should not stimulate, but rather suppress calcitriol production [22], mean calcitriol levels were unchanged or even tended to rise $6 \mathrm{~h}$ after OCL in some HCSF, whereas they fell in NCSF. In the past, a similar observation has been reported by Broadus et al. [20] on a longterm basis: when calcium intake was switched from $400 \mathrm{mg} /$ day to $1000 \mathrm{mg} /$ day in patients with absorptive hypercalciuria, calcitriol fell after 3 days, but returned to baseline values within 14 days. Our study demonstrates that such an inappropriate regulation of calcitriol synthesis contributes both to acute hypercalciuria after OCL (as substantiated by the correlation between total urinary output of calcium and calcitriol levels after OCL), as well as to chronic hypercalciuria (as demonstrated by the inverse relationship between $\mathrm{U}_{\mathrm{Ca}} \times \mathrm{V}$ and $\Delta$ calcitriol $/ \Delta \mathrm{PTH}_{\mathrm{max}}$ ) (Figure 2).

Finally we find that the concept of late absorption of calcium is more a myth than a reality: in only rare subjects, maximum urinary calcium excretion occurred later than $4 \mathrm{~h}$ after OCL. However, in these patients this observation may be clinically relevant after intake of a calcium-rich dinner, since urinary supersaturation late at night and early in the morning, known periods of increased urinary supersaturation [23], would rise further.

In conclusion we demonstrate that the magnitude of 
calciuric response after oral calcium loading depends on both calcitriol production and PTH secretion. In $\mathrm{HCSF}$, secretion of the two calcotropic hormones is in mutual imbalance, i.e. calcitriol production is inappropriately up-regulated with respect to blood calcium, phosphate, and PTH levels. This induces steeper increases in blood calcium early after calciumcontaining meals with more pronounced suppression of PTH secretion and subsequent hypercalciuria. Further studies are needed to better understand the origin of this phenomenon.

Acknowledgements. This study was supported by the Swiss National Science Foundation (Grants No. 32-26428.89 and 32-33543.92).

The authors greatly acknowledge the help of $\mathbf{L}$. Zipperle, K. Farina and $S$. Oetliker from the Calcium Phosphate Laboratory of the Policlinic of Medicine.

\section{References}

1. Coe FL, Bushinsky D. Pathophysiology of idiopathic hypercalciuria. Am J Physiol 1984; 247 (Renal Fluid Electrolyte Physiol 16): F1-F13

2. Nordin BEC, Hodgkinson A, Peacock M. The measurement and the meaning of urinary calcium. Clin Orthop 1967; 52: 293-322

3. Hess $\mathrm{B}$, Jaeger $\mathrm{Ph}$. The tale of parathyroid function in idiopathic hypercalciuria. Scanning Microsc 1993; 7: 403-408

4. Pacifici R, Rothstein M, Rifas $\mathrm{L}$ et al. Increased monocyte interleukin-I activity and decreased vertebral bone density in patients with fasting hypercalciuria. $J$ Clin Endocrinol Metab 1990; $71: 138-145$

5. Broadus AE, Insogna KL, Lang $\mathrm{R}$ et al. A consideration of the hormonal basis and phosphate leak hypothesis of absorptive hypercalciuria. J Clin Endocrinol Metab 1984; 58: 161-169

6. Gray RW, Wilz DR, Caldas AE, Lemann J Jr. The importance of phosphate in regulating plasma $1,25(\mathrm{OH})_{2}$ vitamin $\mathrm{D}$ levels in humans: studies in healthy subjects, in calcium-stone formers and in patients with primary hyperparathyroidism. I Clin Endocrinol Metab 1977; 45: 299-306

7. Zerwekh J, Sakhaee K, Pak CYC. Utility and limitation of calciuric response to oral calcium load as a measure of intestinal calcium absorption: comparison with isotopic fractional calcium absorption. Invest Urol 1981; 19: 161-164
8. Coe FL, Parks JH, Asplin JR. The pathogenesis and treatment of kidney stones. $N$ Engl J Med 1992; 327: 1141-1152

9. Smith LH. Pathogenesis of renal stones. Miner Electrolyte Metab 1987; 13: 214-219

10. Hess B, Casez J-P, Takkinen R, Ackermann D, Jaeger Ph. Relative hypoparathyroidism and calcitriol up-regulation in hypercalciuric calcium renal stone formers-impact of nutrition. Am J Nephrol 1993; 13: 13-26

11. Souci SW, Fachmann W, Kraut H. Food Composition and Nutrition Tables 1986/87, edn 3. Stuttgart, Wissenschaftliche Verlagsgesellschaft, 1986

12. Chiriboga J. Some properties of an oxalic oxidase purified from barley seedlings. Biochem Biophys Res Commun 1963; 11: 277-282

13. Toftegaard Nielsen T. A method for enzymatic determination of citrate in serum and urine. Scand J Clin Lab Invest 1976; 36: 513-519

14. Bucholz AE, Verplough CI, Smith JL. A method for the simultaneous measurement chloride, nitrate, and sulfate in aqueous samples by nonsuppressed ion chromatography. J Chromatogr Sci 1982; 20. 449-501

15. Walton RJ, Bijvoet OLM Nomogram for derivation of renal threshold phosphate concentration. Lancet 1975; 2: 309-310

16. Hodgkinson A, Pyrah LN. The urinary excretion of calcium and inorganic phosphate in 344 patients with calcium stone of renal orıin. $\mathrm{Br} J$ Surg 1958; 46: 10-18

17. Pak CYC, Kaplan R, Bone H, Townsend RN, Waters O. A simple test for the diagnosis of absorptive, resorptive and renal hypercalciurias. N Engl J Med 1975; 292: 497-500

18. Coe FL, Favus MJ, Crockett T et al. Effects of low-calcium diet in urine calcium excretion, parathyroid function and serum 1,25 $(\mathrm{OH})_{2}$ D3 levels in patients with idiopathic hypercalciuria and in normal subjects. Am J Med 1982; 72: 25-32

19. Walling MW. Intestinal calcium and phosphate transport: differential responses to vitamin D3 metabolites. Am J Physio 1977; 233: E488-E494

20. Broadus $\mathrm{AE}$, Insogna $\mathrm{KL}$, Lang $\mathrm{R}$, Ellison $\mathrm{AF}$, Dreyer $\mathrm{BE}$. Evidence for disordered control of 1,25-dihydroxyvitamin $\mathrm{D}$ production in absorptive hypercalciuria. $N$ Engl $J$ Med 1984; 311: 73-80

21. Bataille P, Achard JM, Fournier A et al Diet, vitamin D and vertebral mineral density in hypercalciuric calcium stone formers. Kidney Int 1991; 39: 1193-1205

22. Breslau NA. Normal and abnormal regulation of $1,25-(\mathrm{OH})_{2} \mathrm{D}$ synthesis. Am J Med Sci 1988; 296: 417-425

23. Ahlstrand C, Larsson L, Tiselius HG. Variations in urine composition during the day in patients with calcium oxalate stone disease. $J$ Urol 1984; 131: 77-81 